\title{
Epidemiology of Humanpapilloma virus infection among women in Fujian, China
}

\author{
Conglian $\mathrm{Wu}^{1,3+}{ }^{\dagger}$, Xianjin Zhu ${ }^{1 \dagger}$, Yanli Kang ${ }^{1}$, Yinping Cao', Pingxia Lu', Wenjuan Zhou', Hong Zhou', \\ Yang Zhang ${ }^{1}$ and Yanfang Song ${ }^{2^{*}}$
}

\begin{abstract}
Background: Human papillomavirus (HPV) infection is the main etiological factor for the development of cervical cancer. Here we assessed the prevalence and distribution of HPV genotypes in Fujian population.

Methods: A total of 8678 women aging from 17 to 84 years olds were recruited from the Fujian Medical University Union Hospital in Fujian Province. Every woman had a face-to-face interview. Cervical samples were collected from each participant and HPV screening was conducted using microarray hybridization.

Results: Our study showed that the HPV prevalence in Fujian province was 38.3\%. Among the positive individuals, 70.6\% were detected for single HPV infection, 29.4\% for multiple HPV infections. Further analysis showed that the prevalence of HPV infection significantly increased from 2009 to 2015. The four most common high risk human papillomavirus (HR-HPV) genotypes were HPV16 (8.5\%), HPV52 (7.9\%), HPV58 (6.2\%), HPV 53 (3.5\%), collectively accounting for 60.5\% of all detected HPV infection. Age subgroup analysis showed two peaks for the frequencies of overall and multiple HPV infections, one for the group of women under 25 years old, and the other for the group over 55 years old.
\end{abstract}

Conclusions: HPV infection is becoming serious in Fujian province, which indicates the imperative to implement a HPV vaccination and screening program for this region.

Keywords: Human papillomavirus (HPV), Prevalence, Genotyping, Cervical cancer, Fujian

\section{Background}

Cervical cancer is the fourth most common cancer among women worldwide [1]. In China, cervical cancer is the second most common gynecologic cancers among women, with an increasing incidence and mortality rates in young women [2]. The relationship between cervical cancer and human papillomavirus (HPV) infection is widely studied, and it has been approved that HPV infection plays an important role in the development of cervical cancer during past decades $[3,4]$, so it is necessary for the cervical cancer prevention to detect timely, prevent and decrease HPV infection. So far more than 100 HPV genotypes have been identified and about 40 genotypes can infect the genital tract [5]. According to their associations with cervical cancer and precancerous lesions, HPV genotypes are

\footnotetext{
* Correspondence: syf8881687@hotmail.com

${ }^{\dagger}$ Equal contributors

${ }^{2}$ Department of Laboratory Medicine, Affiliated Renmin Hospital of Fujian University of Traditional Chinese Medicine; Fujian province key Laboratory of Integrated Traditional and Western Immunity Nephrology, 602 Bayiqi Road, Fuzhou 350001, China

Full list of author information is available at the end of the article
}

generally classified into high-risk (HR) and low-risk (LR) genotypes [5]. More than 15 HR-HPV genotypes are associated with the development of cervical cancer, of which HPV 16, 18, 31, 33, 35, 45, 52, and 58 are associated with $90 \%$ of invasive cervical cancers and HPV 16 and 18 are associated with $70 \%$ of invasive cervical cancer $[6,7]$, The LR-HPV genotypes including HPV 6, 11, 42, 43 and 44, are associated with hyperplasic lesions [5]. Considering that the important role of HPV infection in the development of cervical cancer and other associated diseases, HPV screening is strongly advised and has an important prognostic or therapeutic value because it is more sensitive and costeffective than cytology-based screening for detection of cervical cancer [8-12]. HPV screening, especial HR-HPV screening, is useful in the selection of those patients who are at increased risk for cervical cancer and may therefore provide timely prevention and treatment $[8,13]$.

Nowadays, vaccine is crucial in the prevention of HPV infection and cervical cancer. Recently, three licensed HPV vaccines have been implementation in most western 
countries. Cervarix ${ }^{\oplus}$ vaccine is a bivalent $\mathrm{HPV}$ vaccine against HPV16 and 18, Gardasil ${ }^{\circ}$ vaccine is a quadrivalent vaccine against HPV 6, 11, 16, and 18, and Gardasil 9 vaccine would target four types (HPV 6, 11, 16, and 18), and five new HPV types (HPV 31, 33, 45, 52, and 58) [14-16]. Although, three licensed HPV vaccines are shown to have the potential to significantly reduce the burden of cervical cancer, there remain the possibility that non-vaccine HPV genotypes may replace HPV vaccine genotypes as causal agents of cervical precancer and cancer in vaccinated populations [6]. Previous studies have found that HPV prevalence and genotype distribution vary greatly with geographic areas [17]. Thus, it is necessary to survey the prevalence and distribution of HPV genotypes in Fujian province to provide the baseline information on HPV infection status before the available of vaccines.

To date, in Fujian province, there is only one previous report about the prevalence and distribution of HPV infection among 2338 women in 2008-2009 [18], and the available data are limited and outdated. For obtaining a more current dataset, we conducted a study to investigate the overall, age-specific and genotype-specific prevalence of HPV infection among women in this region. Our study would provide guidance for the implement of HPV vaccination programs.

\section{Methods}

\section{Study population}

The study population was originally obtained from the outpatient services of the departments of gynecology, health medical examination of the Fujian Medical University Union Hospital in Fujian Province from January 2009 to December 2015. Every woman attending the gynecological examination had a face-to-face interview. Inclusion criteria were designed for enrolled women who: a) had a history of current or past sexual activity, b) had an intact uterus, c) had no use of vaginal medication or washing presently, d) were physically and mentally competent, e) were not presently pregnant, f) were a permanent resident of the local area, g) were willing to undergo an HPV test and participate in the present study. Finally, 76 samples were excluded because they were duplicate samples from the same women (in this study the first sample was used).Thus, the final study population included 8678 eligible women (age range: $17-84$ years; mean age: 39 years). These studies were performed in accordance with ethical guidelines under the protocols approved by the Institutional Medical Ethics Review Board of Fujian Medical University Union Hospital, Fuzhou, China.

\section{Sample collection and HPV genotyping}

Cervical samples were obtained from women using a cytobrush and used for genomic DNA extraction. Subsequently, HPV DNA was detected and genotyped by flow-through hybridization and gene chip by HybriMax (Chaozhou Hybribio Limited Corporation, Chaozhou, China), in accordance with the manufacturer's instructions. This kit can capture the special HPV DNA strain via oligonucleotide probes immobilized in a nylon membrane. This technology can detect $21 \mathrm{HPV}$ genotypes, including 6 low-risk (LR) genotypes $(6,11,42,43$ and 44, CP8304), and 15 high-risk (HR) genotypes $(16,18,31,33,35,39,45,51,52,53,56,58$, $59,66,68)$. Simultaneously, the positive and negative controls were used to validate the HPV test.

\section{Statistical analysis}

Statistical analysis was performed using SPSS software for windows (version 18.0). We calculate the prevalence of HPV infection by dividing the HPV positive number by total number of samples that were successfully tested for HPV. The binomial 95\% confidence interval (95\% CI) for HPV prevalence was calculated. In addition, we used linear-by-linear association test to analyze the linear relationship between the HPV prevalence and time trends. $P$-value $<0.05$ was considered as statistical significance.

\section{Results}

The overall prevalence of HPV infection

A total of 8678 women were involved in this study, of which 3328 (38.3\%) were positive for HPV infection. Single HPV infection accounted for 27.1\% (2351/8678) of all the participants and $70.6 \%(2351 / 3328)$ of positive samples, and further analysis showed that, among women with single HPV infection, single HR-HPV infection accounted for 59.5\% (1982/3328), while single LR-HPV accounted for 11.1\% (369/3328). Multiple HPV infections accounted for $11.3 \%(977 / 8678)$ of all the participants and 29.4\% (977/ 3328 ) of positive samples, and further analysis showed that, among women with multiple HPV infections, $21.2 \%$ (704/3328) were detected for double infections, $5.4 \%$ (179/3328) for triple infections, and 2.8\% (94/3328) for four or more infections.

\section{Time trends in prevalence of HPV infection}

We analyzed the prevalence of HPV infection in Fujian province from 2009 to 2015 and found that the prevalence of HPV infection significantly increased, ranging from 29.4\% (95\% CI 25.8-32.6\%) in 2009 to $43.4 \%$ (95\% CI 40.9-46.1\%) in 2015 (Table 1). Further analysis showed that, from 2009 to 2015, the prevalence of HPV 39, 51, 52, $53,56,59$, and 68 significantly increased over time, while the prevalence of other HPV genotypes did not change significantly (Table 2).

\section{Genotype-specific prevalence of HPV infection}

A total of $21 \mathrm{HPV}$ genotypes were identified among Fujian women in this study. The prevalence of HR-HPV infection were $33.9 \%$ (2940/8678), substantially higher than that of 
Table 1 Prevalence of HPV in women from Fujian, China

\begin{tabular}{|c|c|c|c|c|c|c|}
\hline Year & Age Median (rang) & HPV positive (n) & HPV negative (n) & Total (n) & Prevalence (\%) & $\begin{array}{l}95 \% \mathrm{Cl} \text { of infection } \\
\text { rate (\%) }\end{array}$ \\
\hline 2009 & $37(18-68)$ & 209 & 503 & 712 & 29.4 & $25.8-32.6$ \\
\hline 2010 & $37(17-71)$ & 268 & 516 & 784 & 34.2 & $31.0-37.4$ \\
\hline 2011 & $38(15-76)$ & 403 & 614 & 1017 & 39.6 & $36.7-42.7$ \\
\hline 2012 & $39(18-84)$ & 499 & 799 & 1298 & 38.4 & $35.7-41.1$ \\
\hline 2013 & $40(15-82)$ & 578 & 905 & 1483 & 39.0 & $36.4-41.7$ \\
\hline 2014 & $41(13-80)$ & 758 & 1215 & 1973 & 38.4 & $36.3-40.3$ \\
\hline 2015 & $41(12-77)$ & 613 & 798 & 1411 & 43.4 & $40.9-46.1$ \\
\hline Total & $39(12-84)$ & 3328 & 5350 & 8678 & 38.3 & $37.3-39.4$ \\
\hline
\end{tabular}

LR-HPV infection $(8.9 \%, 773 / 8678)$. The most prevalent HR-HPV genotype was HPV 16 (8.5\%), followed by HPV 52 (7.9\%), HPV 58 (6.2\%), and HPV 53 (3.5\%). In addition, the most common LR-HPV genotypes were HPV 8304 (3.6\%), HPV 6 (2.3\%) and HPV 11 (2.2\%) (Fig. 1).

\section{Age-specific prevalence of HPV infection}

In this study, all the participants were stratified into 5 groups based on their age. (Table 3). Age-specific prevalence of total HPV infection exhibited a "U-shaped" curve, with the frequencies of $46.3 \%$ (95\% CI 42.3-50.4\%), 34.1\% (95\% CI $32.1-36.0 \%$ ), $35.8 \%$ (95\% CI 34.1-37.4\%), $41.5 \%$ (95\% CI $39.3-43.8 \%$ ), and $51.0 \%$ (95\% CI $47.2-54.9 \%$ ) in different age groups, respectively. The first peak was appeared in the group under $\leq 24$ years of age $(46.3 \% ; 263 / 568)$. Values decreased to $34.1 \%$ in the group 25-34 years of age and contiguously increased to $51.0 \%$ in the group $\geq 55$ years of age ( $\geq 55 ; 51.0 \%)$ (Fig. 2a). The lowest prevalence (19\%, $792 / 2322)$ was found in the 25-34 age groups. Similar age-prevalence curve was also observed in multiple

Table 2 The HPV genotype distribution in Fujian province from 2009 to 2015

\begin{tabular}{|c|c|c|c|c|c|c|c|c|c|c|c|}
\hline \multirow{2}{*}{$\begin{array}{l}\text { HPV } \\
\text { type }\end{array}$} & \multicolumn{7}{|l|}{ Year } & \multirow[t]{2}{*}{ Total } & \multirow{2}{*}{$\begin{array}{l}\text { Frequency for } \\
\text { all sample (\%) }\end{array}$} & \multirow{2}{*}{$\begin{array}{l}\text { Frequency for } \\
\text { positive sample (\%) }\end{array}$} & \multirow{2}{*}{$\begin{array}{l}\text { 95\% Cl for all } \\
\text { samples (\%) }\end{array}$} \\
\hline & 2009 N(\%) & 2010 N(\%) & $2011 \mathrm{~N}(\%)$ & 2012 N(\%) & $2013 \mathrm{~N}(\%)$ & 2014 N(\%) & 2015 N(\%) & & & & \\
\hline 16 & $57(8.0)$ & $70(8.9)$ & $87(8.6)$ & 124(9.6) & 119(8.0) & $164(8.3)$ & $121(8.6)$ & 742 & 8.5 & 22.3 & $8.0-9.1$ \\
\hline 18 & $14(2.0)$ & $22(2.8)$ & $28(2.8)$ & $30(2.3)$ & $34(2.3)$ & $51(2.6)$ & $37(2.6)$ & 216 & 2.5 & 6.5 & $2.2-2.8$ \\
\hline 31 & $12(1.7)$ & $18(2.3)$ & $26(2.6)$ & 24(1.8) & $34(2.3)$ & $39(2.0)$ & $20(1.4)$ & 173 & 2.0 & 5.2 & $1.7-2.3$ \\
\hline 33 & $16(2.2)$ & $22(2.8)$ & 40(3.9) & $32(2.5)$ & $42(2.8)$ & $4(1.7)$ & $37(2.6)$ & 223 & 2.6 & 6.7 & $2.2-2.9$ \\
\hline 35 & $3(0.4)$ & $5(0.6)$ & $10(1.0)$ & $6(0.5)$ & $13(0.9)$ & $11(0.6)$ & 18(1.3) & 66 & 0.8 & 2.0 & $0.6-0.9$ \\
\hline 39 & $5(0.7)$ & $10(1.3)$ & $18(1.8)$ & $23(1.8)$ & $33(2.2)$ & $66(3.3)$ & $24(1.7)$ & 179 & 2.1 & 5.4 & $1.8-2.4$ \\
\hline 45 & $2(0.3)$ & $2(0.3)$ & $4(0.4)$ & $8(0.6)$ & $10(0.7)$ & $5(0.3)$ & $10(0.7)$ & 41 & 0.5 & 1.2 & $0.3-0.6$ \\
\hline 51 & $9(1.3)$ & $4(0.5)$ & $4(0.4)$ & $3(0.2)$ & $23(1.6)$ & $47(2.4)$ & $58(4.1)$ & 148 & 1.7 & 4.4 & $1.4-2.0$ \\
\hline 52 & $36(5.1)$ & $47(6.0)$ & $84(8.3)$ & $84(6.5)$ & $123(8.3)$ & $172(8.7)$ & $143(10.1)$ & 689 & 7.9 & 20.7 & $7.4-8.5$ \\
\hline 53 & $15(2.1)$ & $14(1.8)$ & $34(3.3)$ & $42(3.2)$ & $58(3.9)$ & $71(3.6)$ & $72(5.1)$ & 306 & 3.5 & 9.2 & $3.1-3.9$ \\
\hline 56 & $4(0.6)$ & $13(1.7)$ & $6(0.6)$ & $18(1.4)$ & $18(1.2)$ & $28(1.4)$ & $39(2,8)$ & 126 & 1.5 & 3.8 & $1.2-1.7$ \\
\hline 58 & $33(4.6)$ & $38(4.8)$ & $67(6.6)$ & $81(6.2)$ & $97(6.5)$ & 135(6.8) & $84(6.0)$ & 535 & 6.2 & 16.1 & $5.7-6.7$ \\
\hline 59 & $5(0.7)$ & $8(1.0)$ & $8(0.8)$ & $15(1.2)$ & $13(0.9)$ & $19(1.0)$ & $30(2.1)$ & 98 & 1.1 & 2.9 & $0.9-1.3$ \\
\hline 66 & 10(1.4) & $13(1.7)$ & $17(1.7)$ & $26(2.0)$ & $31(2.1)$ & $31(1.6)$ & $42(3.0)$ & 170 & 2.0 & 5.1 & $1.7-2.2$ \\
\hline 68 & $8(1.1)$ & $8(1.0)$ & $14(1.4)$ & $35(2.7)$ & $27(1.8)$ & $43(2.2)$ & $37(2.6)$ & 172 & 2.0 & 5.2 & $1.7-2.3$ \\
\hline 6 & $22(3.1)$ & $17(2.2)$ & $17(1.7)$ & $28(2.2)$ & $37(2.5)$ & $39(2.0)$ & $37(2.6)$ & 197 & 2.3 & 5.9 & $2.0-2.6$ \\
\hline 11 & $18(2.5)$ & $28(3.6)$ & $27(2.7)$ & $27(2.1)$ & $43(2.9)$ & $33(1.7)$ & 18(1.3) & 194 & 2.2 & 5.8 & $1.9-2.5$ \\
\hline 42 & $3(0.4)$ & $0(0.0)$ & $4(0.4)$ & $7(0.5)$ & $9(0.6)$ & $6(0.3)$ & $37(2.6)$ & 66 & 0.8 & 2.0 & $0.6-1.0$ \\
\hline 43 & $0(0.0)$ & $0(0.0)$ & $0(0.0)$ & $0(0.0)$ & $0(0.0)$ & $3(0.2)$ & $33(2.3)$ & 36 & 0.4 & 1.1 & $0.3-0.6$ \\
\hline 44 & $4(0.6)$ & $2(0.3)$ & $8(0.8)$ & $6(0.5)$ & $7(0.5)$ & $11(0.6)$ & $0(0.0)$ & 38 & 0.4 & 1.1 & $0.3-0.6$ \\
\hline CP8304 & $7(1.0)$ & $20(2.6)$ & $36(3.5)$ & $53(4.1)$ & $74(5.0)$ & $63(3.2)$ & $57(4.0)$ & 310 & 3.6 & 9.3 & $3.2-4.0$ \\
\hline
\end{tabular}




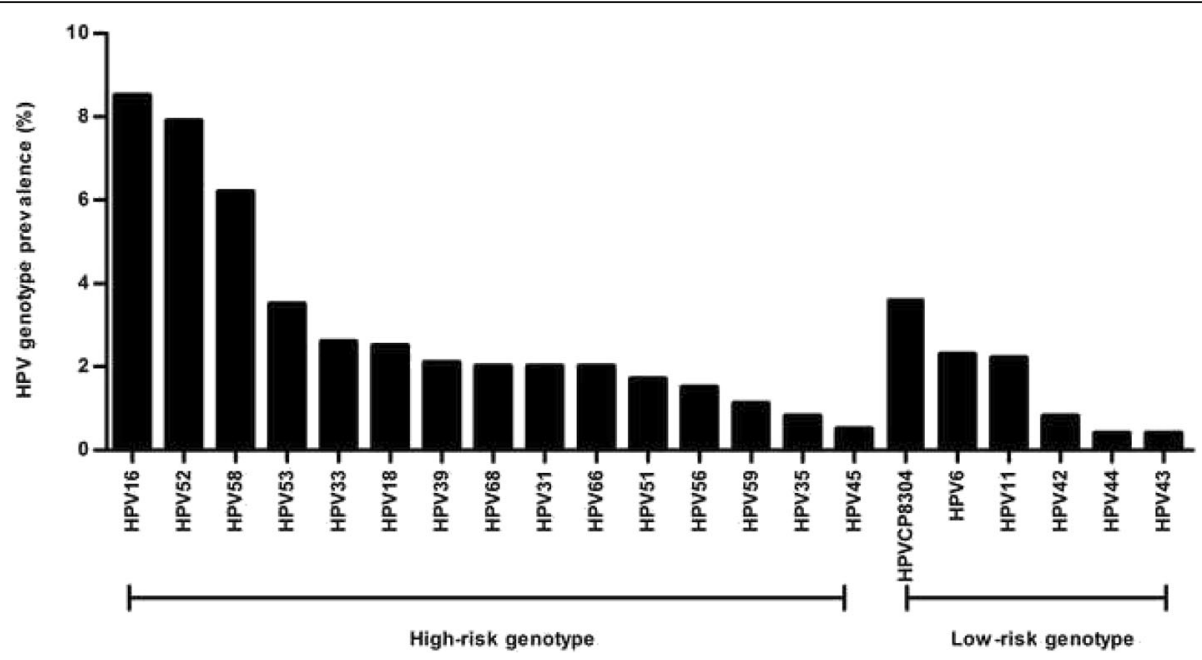

Fig. 1 Distribution of different HPV genotypes in Fujian province. HPV genotypes, including 6 low-risk (LR) genotypes (6, 11, 42, 43 and 44, CP8304), and 15 high-risk (HR) genotypes $(16,18,31,33,35,39,45,51,52,53,56,58,59,66,68)$ were detected by flow-through hybridization and gene chip by HybriMax

HPV infections and single HPV infection (Fig. 2a). However, the prevalence of single HR-HPV exerted an increasing trend with age, and single LR-HPV infection was highest in less than 24 years age group and then decreased significantly with advancing age
(Fig. 2b). We analyzed the age-specific prevalence of the prevalent HR-HPV genotypes (HPV 16, 52, 58 and 53) in Fujian province, and found that the bimodal age distribution was also observed in HPV 16 and 52 but not for HPV 58 and 53 (Fig. 2c).

Table 3 Specific age-related HPV genotype distribution

\begin{tabular}{|c|c|c|c|c|c|c|c|c|c|}
\hline \multirow{2}{*}{$\begin{array}{l}\text { HPV } \\
\text { type }\end{array}$} & \multicolumn{5}{|c|}{ Age group (year) } & \multirow{2}{*}{$\begin{array}{l}\text { HPV positive } \\
\text { (N) }\end{array}$} & \multirow{2}{*}{$\begin{array}{l}\text { Frequency for } \\
\text { all sample (\%) }\end{array}$} & \multirow{2}{*}{$\begin{array}{l}\text { Frequency for } \\
\text { positive sample (\%) }\end{array}$} & \multirow{2}{*}{$\begin{array}{l}\text { 95\% Cl for all } \\
\text { samples (\%) }\end{array}$} \\
\hline & $\leq 24 \mathrm{~N}(\%)$ & $25 \sim 34 \mathrm{~N}(\%)$ & $35 \sim 44 \mathrm{~N}(\%)$ & $45 \sim 54 \mathrm{~N}(\%)$ & $\geq 55 \mathrm{~N}(\%)$ & & & & \\
\hline 16 & $56(9.9)$ & $180(7.8)$ & $259(7.9)$ & 172(9.0) & $75(12.2)$ & 742 & 8.6 & 22.3 & $8.0-9.1$ \\
\hline 18 & $17(3.0)$ & $46(2.0)$ & $79(2.4)$ & $54(2.8)$ & $20(3.2)$ & 216 & 2.5 & 6.5 & $2.2-2.8$ \\
\hline 31 & $14(2.5)$ & $36(1.6)$ & $70(2.1)$ & $36(1.9)$ & $17(2.8)$ & 173 & 2.0 & 5.2 & $1.7-2.3$ \\
\hline 33 & $12(2.1)$ & $46(2.0)$ & $78(2.4)$ & $59(3.1)$ & $28(4.5)$ & 223 & 2.6 & 6.7 & $2.2-2.9$ \\
\hline 35 & $4(0.7)$ & $16(0.7)$ & $26(0.8)$ & $11(0.6)$ & $9(1.5)$ & 66 & 0.8 & 2.0 & $0.6-0.9$ \\
\hline 39 & $13(2.3)$ & $47(2.0)$ & $62(1.9)$ & $39(2.0)$ & $18(2.9)$ & 179 & 2.1 & 5.4 & $1.8-2.4$ \\
\hline 45 & $3(0.5)$ & $6(0.3)$ & $12(0.4)$ & $12(0.6)$ & $8(1.3)$ & 41 & 0.5 & 1.2 & $0.3-0.6$ \\
\hline 51 & $14(2.5)$ & $31(1.3)$ & $49(1.5)$ & $38(2.0)$ & $16(2.6)$ & 148 & 1.7 & 4.4 & $1.4-2.0$ \\
\hline 52 & $54(9.5)$ & $173(7.5)$ & $209(6.4)$ & 180(9.4) & 73(11.9) & 689 & 7.9 & 20.7 & $7.4-8.5$ \\
\hline 53 & $24(4.2)$ & $65(2.8)$ & $106(3.2)$ & 68(3.6) & $43(7.0)$ & 306 & 3.5 & 9.2 & $3.1-3.9$ \\
\hline 56 & $7(1.2)$ & $33(1.4)$ & $29(0.9)$ & $35(1.8)$ & $22(3.6)$ & 126 & 1.5 & 3.8 & $1.2-1.7$ \\
\hline 58 & $32(5.6)$ & $101(4.3)$ & $197(6.0)$ & $147(7.7)$ & $58(9.4)$ & 535 & 6.2 & 16.1 & $5.7-6.7$ \\
\hline 59 & $25(4.4)$ & $11(0.5)$ & $27(0.8)$ & $19(1.0)$ & $16(2.6)$ & 98 & 1.1 & 2.9 & $0.9-1.3$ \\
\hline 66 & $17(3.0)$ & $45(1.9)$ & $62(1.9)$ & $27(1.4)$ & 19(3.1) & 170 & 2.0 & 5.1 & $1.7-2.2$ \\
\hline 68 & $9(1.6)$ & $42(1.8)$ & 63(1.9) & $41(2.2)$ & $17(2.8)$ & 172 & 2.0 & 5.2 & $1.7-2.3$ \\
\hline 6 & $53(9.3)$ & $57(2.5)$ & $54(1.7)$ & $21(1.1)$ & $12(1.9)$ & 197 & 2.3 & 5.9 & $2.0-2.6$ \\
\hline 11 & $52(9.2)$ & $62(2.7)$ & $47(1.4)$ & $22(1.2)$ & $11(1.8)$ & 194 & 2.2 & 5.8 & $1.9-2.5$ \\
\hline 42 & $7(1.2)$ & $16(0.7)$ & $16(0.5)$ & $16(0.8)$ & $11(1.8)$ & 66 & 0.8 & 2.0 & $0.6-1.0$ \\
\hline 43 & $5(0.9)$ & $10(0.4)$ & $9(0.3)$ & $7(0.4)$ & $5(0.8)$ & 36 & 0.4 & 1.1 & $0.3-0.6$ \\
\hline 44 & $5(0.9)$ & $8(0.3)$ & $11(0.3)$ & $6(0.3)$ & $8(1.3)$ & 38 & 0.4 & 1.1 & $0.3-0.6$ \\
\hline CP8304 & $33(5.8)$ & $68(2.9)$ & $111(3.4)$ & $64(3.4)$ & $34(5.5)$ & 310 & 3.6 & 9.3 & $3.2-4.0$ \\
\hline
\end{tabular}




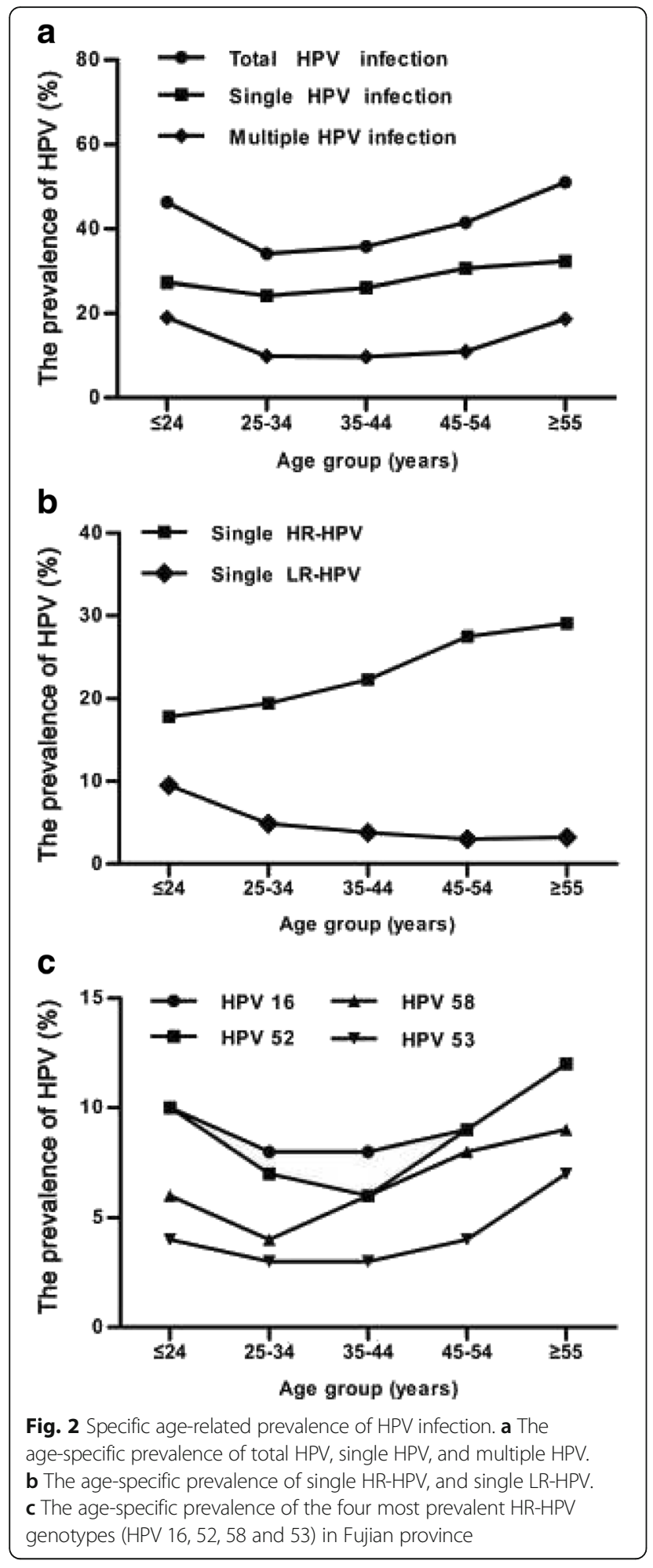

\section{Discussion}

It has been demonstrated that HPV, particularly HR-HPV types, is major causative factors in the development of cervical cancer [3, 19]. However, HPV genotypes may exhibit differing distributions according to geographic region. In this study, we investigated the prevalence of HPV infection in Fujian province, China.

Our results showed that the overall prevalence of HPV infection in Fujian province was 38.3\%. HPV infection rate in Fujian province was significantly higher than that in Henan (22.8\%), Zhejiang (13.3\%), and a previous study in Fujian province (22.5\%), but was similar to that in Harbin (36.5\%) [18, 20-22]. Considering the same laboratory methods method (flow-through hybridization methods) used for HPV infection detection in these reports, the difference in the prevalence of HPV infection might primarily be attributed to differences in the geographical regions. In additional, survey period may be part of the reason: survey period in our study is 2009-2015, and survey period in Luoyang, Zhejiang, Harbin is 2012-2013 [22], 2006-2008 [20], May to December of 2011 [21], respectively. Importantly, the prevalence of HPV infection in $\mathrm{Fu}$ jian province increased significantly, ranging from $29.4 \%$ in 2009 to $43.4 \%$ in 2015 . These results suggested that HPV infection in Fujian province has reached the level of "HPV-heavy-burden" and the infection rate increased with years. The possible reason for increase HPV prevalence over time in Fujian province was that, with the economic development and the increase of international communication since the late 1990's in Fujian province, the view of people toward sexual behavior was really beginning to change. The number of sexual partners has increased in young women and the age of sexual debut become earlier over time. Such increased sexual activities may increase the exposure of HPV, thus potentially lead to an increase over the years in prevalence of HPV. In addition, the absence of the prevention and regular screening of HPV infection also lead to an increased prevalence of HPV infection. However, the exact reasons for the increase of HPV prevalence in Fujian province still remain unclear. Considering the heavy burden of HPV infection, it is imperative to implement HPV screening and vaccines program for this region.

The analysis for genotype-specific prevalence of HPV infection shown that the most common HR-HPV genotype was HPV 16, followed by HPV 52, 58, 53, and 33, whereas HPV 18 was in a relatively low prevalence. The most common LR-HPV genotype was HPV CP8304, followed by $6,11,42$ and 43 . The results in this study were different from most previous studies in other region of china. For example, in Harbin province, main genotypes are HPV 16, 52, 58, 18 and 45 [21]. In Luoyang province, main genotypes are HPV 16, 58, 33, 56 and 35 [22]. And in Zhejiang province, main genotypes are HPV 52, 16, 58, 68, 81 [20]. These studies show that HPV 16 plays a predominant role in all regions, but other prevalent genotypes vary in different regions. Accordingly, the research for genotypes-specific prevalence 
of HPV infection in various regions would provide guidance for developing more effective HPV vaccine for these regions. In addition, our results were also different from previous report of Fujian, which showed that the top $5 \mathrm{HPV}$ genotypes were HPV 52, 16, 18, 33 and 53 [18]. We speculate that this difference may be caused by study period.

Several studies have shown that HPV 52 and HPV 58 are more prevalent genotypes and predominantly associated with the development of cervical cancer in Asian [23-25]. In China, particularly in southern and coastal regions, these two genotypes are found to be more prevalent among women with cervical cancer and precancerous lesion compared to other regions [26]. In this study, we found that the prevalence of HPV 52 and HPV 58 was ranked second and third in Fujian province. Interestingly, in this study, we found that the prevalence of HPV 53 infection in Fujian province was ranked fourth. This result was not very common in other researches and revealed the special distribution of HRHPV in Fujian population. It has been reported that HPV 53 is associated with cervical carcinoma [18]. Considering that the vaccines are types-specific, current HPV vaccines cannot provide complete protection against non-vaccine HPV genotypes. When considering a vaccine, the data from this study show that Cervarix vaccine (targets HPV 16, 18) and Gardasil vaccine (targets HPV $6,11,16,18$ ) only cover $27.9 \%$ and $37.8 \%$ of infections, respectively. When considering Gardasil 9 vaccine (targets HPV $6,11,16,18,31,33,45,52,58$ ), the potential for HPV prevention would rise to $74.2 \%$ in Fujian women.

Previous studies in China have observed that HPV prevalence has two peaks in terms of age, while the peak age varied among different studies [8, 27, 28]. The first peak is generally found in younger women, usually in their early twenties, and the other peak usually appear in menopausal women. In agreement with previous studies, our study found that the age-specific prevalence of total HPV, single HPV and multiple HPV all formed an approximate U-shaped curve with two peaks, one at the $\leq 24$ age group and the other at the $\geq 55$ age group. The first peak observed in younger women $(\leq 24$ years old) may account for sexual activity [29] and immature immunity to HPV [30], thus, it is the optimum time to offer HPV vaccines to adolescent females before sexual debut and HPV exposure. HPV infection rate was decreased to the lowest at the 25-34 age groups. This phenomenon might attribute mostly to their mature immunity to HPV, which have greater ability to prevent and clear HPV infections. In addition, women in the 2534 age groups were generally during the reproductive age, a period in which some of women are more likely to visit the gynecologic clinic for reasons linked to reproduction, therefore they have higher probability to be "healthy". The second peak in older women may account for HPV persistence and reactivation of latent viruses due to physiologic and immunologic dysregulation during menopausal transition [31]. Considering that the older women with HPV infection are prone to have viral persistence [32, 33], they may have higher risk for the development of cervical cancer. Accordingly, comprehensive, efficient and regular cervical screening programs should be implemented for older women with HPV infection.

Some studies have reported that multiple infections are frequently detected in different grades of cervical cancer [34]. In this study, we found that multiple HPV infections accounted for $29.4 \%$ of all infections. Our finding is similar to the previous studies which multiple infection accounts for $26-38 \%$ of all infections in China [35, 36]. The role of multiple HPV infections on cervical cancer remains debatable. Some studies have reported that multiple infections are associated with an increased risk of precancerous lesions and cervical cancer [37, 38]. However, other studies reported that the risk of developing cervical cancer in women with multiple HPV infections is no greater than for those with single HPV infection [39, 40]. Therefore, the potential role of multiple infections in cervical cancer needs further investigation.

There were several limitations to this study. The study population was originally obtained from the outpatient services of the departments of gynecology and health medical examination of the Fujian Medical University Union Hospital. To overcome this shortcoming, all women who visited cervical cancer screening and the Health Medical Examination Center from January 2009 to December 2015 were enrolled in study population, but for consecutive females who attend the center, we only collected the HPV results of the first examination, and the next HPV test results were excluded. In the future, a population-based study should be performed to investigate the HPV infection. In addition, the cytological data on the enrolled individuals were not collected in this study, thus, we did not have the data of cervical lesions classification, which may impact on base prevalence.

\section{Conclusions}

Our study provides the data on the prevalence and distribution of HPV infection in Fujian province, the southeast of China. Our results suggest that HPV infection in Fujian province has reached the level of "HPV-heavy-burden" and increased with years. The four most frequent HRHPV genotypes is HPV $16,52,58,53$. Our results would provide baseline information for estimating HPV vaccines and screening for this region. 


\section{Abbreviations}

HPV: Human papillomavirus; HR: High-risk; HR-HPV: High risk human papillomavirus; LR: Low risk; LR-HPV: Low risk human papillomavirus

\section{Acknowledgments}

We would like to thank the doctors and nurses in departments of gynecology, health medical examination of the Fujian Medical University Union Hospital for help in this study.

\section{Funding}

This study was supported by Natural Science Foundation of Fujian Province (2015 J01400, 2016 J01569), and the Training Project for Young and Middleaged Core Talents in Health System of Fujian Province (2016-ZQN-31). The funders had no role in study design, data collection and analysis, decision to publish, or preparation of the manuscript.

\section{Availability of data and materials}

The datasets used and/or analysed during the current study are available from the corresponding author on reasonable request.

\section{Authors' contributions}

$Y S$ and $X Z$ conceived the research and took overall supervision in the study. $C W, Y K, Y C, P L, W Z, H Z$ and $Y Z$ performed experiments. $X Z, Y S$ and $C W$ performed data analysis. XZ, YS and CW wrote the manuscript. XZ, YS and $\mathrm{CW}$ contributed to the discussion of results and to the review of the manuscript. All authors read and approved the final manuscript.

\section{Ethics approval and consent to participate}

These studies were performed in accordance with ethical guidelines under the protocols approved by the Institutional Medical Ethics Review Board of Affiliated Union Hospital of Fujian Medical University, Fuzhou, China. All adults who participated in the study signed a consent form.

\section{Consent for publication}

Not applicable.

\section{Competing interests}

The authors declare that they have no competing interests.

\section{Publisher's Note}

Springer Nature remains neutral with regard to jurisdictional claims in published maps and institutional affiliations.

\section{Author details}

${ }^{1}$ Department of Laboratory Medicine, Fujian Medical University Union Hospital, 29 Xinquan Road, Fuzhou 350001, China. ${ }^{2}$ Department of Laboratory Medicine, Affiliated Renmin Hospital of Fujian University of Traditional Chinese Medicine; Fujian province key Laboratory of Integrated Traditional and Western Immunity Nephrology, 602 Bayiqi Road, Fuzhou 350001, China. ${ }^{3}$ Department of Laboratory Medicine, The First Hospital of Quanzhou Affiliated to Fujian Medical University, 248-252 East Street, Quanzhou, Fujian 362000, China.

Received: 11 January 2017 Accepted: 30 July 2017 Published online: 03 August 2017

\section{References}

1. Ferlay J, Soerjomataram I, Dikshit R, Eser S, Mathers C, Rebelo M, Parkin DM, Forman D, Bray F. Cancer incidence and mortality worldwide: sources, methods and major patterns in GLOBOCAN 2012. Int J Cancer. 2015;136(5): E359-86.

2. Kim K, Zang R, Choi SC, Ryu SY, Kim JW. Current status of gynecological cancer in China. J Gynecol Oncol. 2009:20(2):72-6.

3. Pierce Campbell CM, Menezes LJ, Paskett ED, Giuliano AR. Prevention of invasive cervical cancer in the United States: past, present, and future. Cancer Epidemiol Biomark Prev. 2012;21(9):1402-8.

4. Walboomers JM, Jacobs MV, Manos MM, Bosch FX, Kummer JA, Shah KV, Snijders PJ, Peto J, Meijer CJ, Munoz N. Human papillomavirus is a necessary cause of invasive cervical cancer worldwide. J Pathol. 1999;189(1):12-9.

5. Baseman JG, Koutsky LA. The epidemiology of human papillomavirus infections. J Clin Virol. 2005;32(Suppl 1):S16-24.
6. Herrero R. Human papillomavirus (HPV) vaccines: limited cross-protection against additional HPV types. J Infect Dis. 2009;199(7):919-22.

7. de Sanjose S, Quint WG, Alemany L, Geraets DT, Klaustermeier JE, Lloveras B, Tous S, Felix A, Bravo LE, Shin HR, et al. Human papillomavirus genotype attribution in invasive cervical cancer: a retrospective cross-sectional worldwide study. Lancet Oncol. 2010;11(11):1048-56.

8. Zhao FH, Lin MJ, Chen F, Hu SY, Zhang R, Belinson JL, Sellors JW, Franceschi $\mathrm{S}$, Qiao YL, Castle PE, et al. Performance of high-risk human papillomavirus DNA testing as a primary screen for cervical cancer: a pooled analysis of individual patient data from 17 population-based studies from China. Lancet Oncol. 2010;11(12):1160-71.

9. Priebe AM. 2012 cervical cancer screening guidelines and the future role of HPV testing. Clin Obstet Gynecol. 2013;56(1):44-50.

10. Sankaranarayanan R, Nene BM, Shastri SS, Jayant K, Muwonge R, Budukh AM, Hingmire S, Malvi SG, Thorat R, Kothari A, et al. HPV screening for cervical cancer in rural India. N Engl J Med. 2009:360(14):1385-94.

11. Ronco G, Dillner J, Elfstrom KM, Tunesi S, Snijders PJ, Arbyn M, Kitchener H, Segnan N, Gilham C, Giorgi-Rossi P, et al. Efficacy of HPV-based screening for prevention of invasive cervical cancer: follow-up of four European randomised controlled trials. Lancet. 2014:383(9916):524-32.

12. Ronco G, Giorgi-Rossi P, Carozzi F, Confortini M, Dalla Palma P, Del Mistro A, Ghiringhello B, Girlando S, Gillio-Tos A, De Marco L, et al. Efficacy of human papillomavirus testing for the detection of invasive cervical cancers and cervical intraepithelial neoplasia: a randomised controlled trial. Lancet Oncol. 2010;11(3):249-57.

13. Levin CE, Sellors J, Shi JF, Ma L, Qiao YL, Ortendahl J, O'Shea MK, Goldie SJ. Cost-effectiveness analysis of cervical cancer prevention based on a rapid human papillomavirus screening test in a high-risk region of China. Int J Cancer. 2010:127(6):1404-11.

14. Banura C, Mirembe FM, Katahoire AR, Namujju PB, Mbonye AK, Wabwire FM Epidemiology of HPV genotypes in Uganda and the role of the current preventive vaccines: a systematic review. Infect Agent Cancer. 2011;6(1):11.

15. Wheeler CM, Hunt WC, Cuzick J, Langsfeld E, Pearse A, Montoya GD, Robertson M, Shearman CA, Castle PE, New Mexico HPVPRSC. A populationbased study of human papillomavirus genotype prevalence in the United States: baseline measures prior to mass human papillomavirus vaccination. Int J Cancer. 2013;132(1):198-207.

16. Printz C. FDA approves Gardasil 9 for more types of HPV. Cancer. 2015; 121(8):1156-7.

17. de Sanjose S, Diaz M, Castellsague X, Clifford G, Bruni L, Munoz N, Bosch FX. Worldwide prevalence and genotype distribution of cervical human papillomavirus DNA in women with normal cytology: a meta-analysis. Lancet Infect Dis. 2007;7(7):453-9.

18. Wu D, Cai L, Huang M, Zheng Y, Yu J. Prevalence of genital human papillomavirus infection and genotypes among women from Fujian province, PR China. Eur J Obstet Gynecol Reprod Biol. 2010;151(1):86-90.

19. Clifford GM, Smith JS, Aguado T, Franceschi S. Comparison of HPV type distribution in high-grade cervical lesions and cervical cancer: a metaanalysis. Br J Cancer. 2003:89(1):101-5

20. Ye J, Cheng X, Chen X, Ye F, Lu W, Xie X. Prevalence and risk profile of cervical human papillomavirus infection in Zhejiang Province, southeast China: a population-based study. Virol J. 2010;7:66.

21. Sun B, He J, Chen X, He M, He Z, Wang Y, Shang Q, Yu L, Wei L: Prevalence and genotype distribution of human papillomavirus infection in Harbin, Northeast China Arch Virol 2013, 159(5):1027-1032.

22. Wang X-C, Sun L-Q, Ma L, Li H-X, Wang X-L, Wang X, Yun T, Meng N-L, LV D-L. Prevalence and genotype distribution of human papillomavirus among women from Henan, China. Asian Pac J Cancer Prev. 2014;15(17):7333-6.

23. Bhatla N, Lal N, Bao YP, Ng T, Qiao YL. A meta-analysis of human papillomavirus type-distribution in women from South Asia: implications for vaccination. Vaccine. 2008:26(23):2811-7.

24. Bao YP, Li N, Smith JS, Qiao YL. members a: human papillomavirus type distribution in women from Asia: a meta-analysis. Int J Gynecol Cancer. 2008;18(1):71-9.

25. Kim MJ, Kim JJ, Kim S. Type-specific prevalence of high-risk human papillomavirus by cervical cytology and age: data from the health checkups of 7,014 Korean women. Obstet Gynecol Sci. 2013:56(2):110-20.

26. Li J, Huang R, Schmidt JE, Qiao Y-L. Epidemiological features of human papillomavirus (HPV) infection among women living in mainland China. Asian Pac J Cancer Prev. 2013;14(7):4015-23. 
27. Zhi YF, Cha XX, Li XF, Qiu C, Rong SH. Prevalence and genotype distribution of human papillomavirus in women in the Henan Province. Genet Mol Res. 2015;14(2):5452-61.

28. Liu XX, Fan XL, Yu YP, Ji L, Yan J, Sun AH. Human papillomavirus prevalence and type-distribution among women in Zhejiang Province Southeast China: a cross-sectional study. BMC Infect Dis. 2014;14:708.

29. Zhao F-H, Tiggelaar SM, Hu S-Y, Xu L-N, Hong Y, Niyazi M, Gao X-H, Ju L-R, Zhang $L-Q$, Feng $X-X$, et al. A multi-center survey of age of sexual debut and sexual behavior in Chinese women: suggestions for optimal age of human papillomavirus vaccination in China. Cancer Epidemiol. 2012;36(4):384-90.

30. Winer RL, Feng Q, Hughes JP, O'Reilly S, Kiviat NB, Koutsky LA. Risk of female human papillomavirus acquisition associated with first male sex partner. J Infect Dis. 2008;197(2):279-82.

31. Althoff KN, Paul P, Burke AE, Viscidi R, Sangaramoorthy M, Gravitt PE. Correlates of cervicovaginal human papillomavirus detection in perimenopausal women. J Women's Health (Larchmt). 2009;18(9):1341-6.

32. Castle PE, Schiffman M, Herrero R, Hildesheim A, Rodriguez AC, Bratti MC, Sherman ME, Wacholder S, Tarone R, Burk RD. A prospective study of age trends in cervical human papillomavirus acquisition and persistence in Guanacaste Costa Rica. J Infect Dis. 2005;191(11):1808-16.

33. Goodman MT, Shvetsov YB, McDuffie K, Wilkens LR, Zhu X, Thompson PJ, Ning L, Killeen J, Kamemoto L, Hernandez BY. Prevalence, acquisition, and clearance of cervical human papillomavirus infection among women with normal cytology: Hawaii human papillomavirus cohort study. Cancer Res. 2008;68(21):8813-24

34. Schmitt M, Depuydt C, Benoy I, Bogers J, Antoine J, Arbyn M, Pawlita M, Group VS. Multiple human papillomavirus infections with high viral loads are associated with cervical lesions but do not differentiate grades of cervical abnormalities. J Clin Microbiol. 2013;51(5):1458-64.

35. Dai M, Bao YP, Li N, Clifford GM, Vaccarella S, Snijders PJ, Huang RD, Sun LX, Meijer CJ, Qiao YL, et al. Human papillomavirus infection in Shanxi Province, People's Republic of China: a population-based study. Br J Cancer. 2006; 95(1):96-101.

36. Zhao R, Zhang WY, Wu MH, Zhang SW, Pan J, Zhu L, Zhang YP, Li H, Gu YS, Liu XZ. Human papillomavirus infection in Beijing, People's Republic of China: a population-based study. Br J Cancer. 2009;101(9):1635-40.

37. Lee SA, Kang D, Seo SS, Jeong JK, Yoo KY, Jeon YT, Kim JW, Park NH, Kang SB, Lee HP, et al. Multiple HPV infection in cervical cancer screened by HPVDNAChip. Cancer Lett. 2003;198(2):187-92.

38. van der Graaf Y, Molijn A, Doornewaard H, Quint W, van Doorn $L$, van den Tweel J. Human papillomavirus and the long-term risk of cervical neoplasia. Am J Epidemiol. 2002;156(2):158-64.

39. Levi JE, Kleter B, Quint WG, Fink MC, Canto CL, Matsubara R, Linhares I, Segurado A, Vanderborght B, Neto JE, et al. High prevalence of human papillomavirus (HPV) infections and high frequency of multiple HPV genotypes in human immunodeficiency virus-infected women in Brazil. J Clin Microbiol. 2002;40(9):3341-5.

40. Levi JE, Fernandes S, Tateno AF, Motta E, Lima LP, Eluf-Neto J, Pannuti CS. Presence of multiple human papillomavirus types in cervical samples from HIV-infected women. Gynecol Oncol. 2004;92(1):225-31.

\section{Submit your next manuscript to BioMed Central and we will help you at every step:}

- We accept pre-submission inquiries

- Our selector tool helps you to find the most relevant journal

- We provide round the clock customer support

- Convenient online submission

- Thorough peer review

- Inclusion in PubMed and all major indexing services

- Maximum visibility for your research

Submit your manuscript at www.biomedcentral.com/submit

) Biomed Central 